\title{
Oficinas de estimulação cognitiva adaptadas para idosos analfabetos com transtorno cognitivo leve
}

\author{
Workshops for cognitive stimulation adapted for elderly illiterate individuals with mild cognitive impairment \\ Talleres de estimulación cognitiva adaptadas para ancianos analfabetos con deterioro cognitivo leve
}

\section{Izabel Borges dos Santos', Lucy Gomes", Neuza Moreira de Matos', Maria Sueli do Vale', Fernando Borges dos Santos"', Carmen Jansen Cardenas", Vicente Paulo Alves"}

'Universidade Católica de Brasília, Curso de Enfermagem, Mestre em Gerontologia. Brasília-DF, Brasil.

"Universidade Católica de Brasília, Curso de Mestrado em Gerontologia. Brasília-DF, Brasil.

I'I Universidade Católica de Brasília, Curso de Medicina (Graduando). Brasília-DF, Brasil.

Submissão: 19-09-2011 Aprovação: 20-12-2012

\section{RESUMO}

Oficinas de estimulação cognitiva para idosos analfabetos com transtorno cognitivo leve é um tema pouco pesquisado. Objetivou-se verificar a autopercepção da memória em idosos analfabetos com transtorno cognitivo leve, antes e após oficinas de estimulação cognitiva, adaptadas para analfabetos. Trata-se de uma pesquisa qualitativa, realizada na Unidade de Saúde de Taguatinga-DF, envolvendo 63 idosos: 22 no Grupo Experimental (GE), com 10 oficinas; 21 no Grupo Controle 1 (GC1), com 10 palestras; e 20 no Grupo Controle 2 (GC2), sem intervenção. Foram realizadas entrevistas semiestruturadas antes e após intervenções, perguntando-se sobre memória. Aos GE e GC1 foram oferecidas atividades semanais de duas horas. A idade média foi 72,8 anos, $92 \%$ do sexo feminino. Na pré-intervenção, $82 \%$ haviam piorado memória no último ano. Na pósintervenção, GC1 e GC2 mantiveram alterações da memória, enquanto GE melhorou cognição. Conclui-se que as oficinas e palestras proporcionaram melhora na funcionalidade e socialização/integração.

Descritores: Idoso; Transtorno Cognitivo Leve; Estimulação cognitiva; Enfermagem.

\section{ABSTRACT}

The aim of this study was to assess the self-perception of memory in elderly illiterate with mild cognitive impairment, before and after workshops of cognitive stimulation adapted for illiterate individuals. The research was qualitative, held at the Health Unit of Taguatinga-DF, involving 63 elderly illiterate: 22 in the experimental group (EG), with 10 workshops; 21 in control group 1 (CG1), with 10 lectures; and 20 in the control group 2 (GC2), without intervention. Semi-structured interviews were carried on before and after the interventions, asking about memory status. The activities offered weekly to EG and CG1 have had two hours of duration. The mean age of the participants was 72.8 years, and $92 \%$ were female. In pre-intervention, $82 \%$ reported worsening memory during the last year. In post-intervention, CG1 and CG2 kept memory changes, while EG improved cognition. One concludes that the provided workshops and lectures improved functionality and socialization / integration.

Key words: Aged; Mild Cognitive Impairment; Cognitive Stimulation; Nursing.

\section{RESUMEN}

Objetivó-se evaluar la percepción subjetiva de la memoria en ancianos analfabetos con deterioro cognitivo leve, antes y después de talleres para estimulación cognitiva adaptada para personas analfabetas. Participaran 63 ancianos: 22 en el grupo experimental (GE) con 10 talleres; 21 en el grupo control 1 (GC1), con 10 conferencias sobre salud; y 20 en el grupo control 2 (CG2), sin intervención. Fueron realizadas entrevistas semi estructuradas antes y después de las intervenciones, preguntandose sobre la memoria. Para los del GE e GC1 fueran ofrecidas actividades semanales de dos horas. La edad media de los participantes fue de 72,8 años, $92 \%$ eran del sexo femenino. En la pre-intervención, $82 \%$ reportaran deterioro en la memoria durante el último año. En la pos-intervención, los del CG1 y del CG2 mantuvieron los cambios en la memoria, mientras que los del GE mejoraron la cognición. Concluí-se que los talleres y conferencias produjeron mejora en la memoria de los ancianos en la funcionalidad y en la socialización/integración.

Palabras clave: Anciano; Deterioro Cognitivo Leve; Estimulación cognitiva; Enfermería. 


\section{INTRODUÇÃO}

Entre os idosos brasileiros encontra-se alto índice de analfabetismo, atingindo 5,1 milhões de habitantes, acrescidos dos analfabetos funcionais que são aqueles com menos de quatro anos de estudo ${ }^{(1)}$.

Com o envelhecimento, pode ocorrer deterioração em diferentes áreas da cognição dependente de processos fisiológicos que se alteram com a idade, gerando declínio cognitivo de início e progressão variáveis. Este declínio pode-se relacionar aos fatores educacionais, de saúde, bem como ao nível intelectual global e às capacidades mentais específicas do indivíduo ${ }^{(2)}$. Estas perturbações são percebidas pelos idosos, especialmente quando comparam seu desempenho atual com o apresentado no passado. Além das dificuldades em armazenar informações e resgatá-las, referem ainda prejuízo ocupacional e social. Diante dessas mudanças decorrentes da idade, especialmente entre os idosos analfabetos, ocorrem autoabandono, perda da autoestima, isolamento da sociedade e até do ambiente familiar ${ }^{(3)}$.

Transtorno Cognitivo Leve (TCL) é definido como o estado transitório entre envelhecimento normal e demência, refletindo situação clínica na qual a pessoa apresenta queixas de memória e evidências de alterações cognitivas que resultam em dificuldade para recordar nomes, número de telefones e objetos guardados, porém não satisfazendo os critérios para possível ou provável doença de Alzheimer ${ }^{(4)}$. Para ser caracterizado como portador de TCL, o indivíduo deve preencher os critérios de queixa de memória confirmada por informante ou familiar, ter funções cognitivas gerais preservadas e manter as atividades de vida diária (AVD). O diagnóstico de TCL é tarefa complexa e ainda não bem sistematizado nos idosos ${ }^{(5)}$. Consequentemente há crescente interesse em intervenções que possibilitem a manutenção da capacidade cerebral desta população.

A pesquisa atual teve como objetivo verificar a autopercepção da memória em indivíduos idosos analfabetos com TCL, antes e após a realização de oficinas de jogos e brincadeiras de estimulação cognitiva, adaptadas para analfabetos (OECA).

\section{MATERIAL E MÉTODO}

Trata-se de pesquisa qualitativa, realizada na Unidade Mista de Saúde de Taguatinga, da Secretaria do Estado de Saúde do Distrito Federal (UMST-DF), serviço de referência para atendimento aos indivíduos idosos. Foi aprovada pelo Comitê de Ética da Fundação de Ensino e Pesquisa em Ciências da Saúde (FEPECS), do Distrito Federal, sob o Parecer $n^{\circ}$ 080/09 em 11/05/2009.

Foram critérios de inclusão na amostra: idade igual ou superior a 60 anos; analfabetismo; diagnóstico de TCL; e acompanhamento clínico com médico geriatra da UMST-DF.

Os critérios de exclusão foram: diagnóstico de demência (possível/provável demência de Alzheimer, de Parkinson e outros tipos); acompanhamento psiquiátrico; uso de medicação controlada que pudesse interferir na cognição e nas respostas ao instrumento de coleta de dados; e diagnóstico de possível depressão, ou uso de medicações antidepressivas. Para se concluir sobre possível depressão, foi aplicada a Escala de Depressão Geriátrica de Yesavage e Brink ${ }^{(6)}$, versão resumida com 15 itens.

O diagnóstico de TCL foi estabelecido por médico geriatra da UMST-DF, seguindo os critérios de Petersen ${ }^{(7)}$. Os idosos incluídos foram orientados para informar ao pesquisador caso iniciassem nova medicação, a fim de se excluir possível interferência desta na cognição.

Os idosos analfabetos com TCL foram inseridos, seguindo a ordem de atendimento no Serviço, formando-se três grupos: os primeiros 22 idosos foram englobados no grupo experimental (GE); os 21seguintes compuseram o grupo controle 1 (GC1); e os próximos 20 formaram o grupo controle 2 (GC2), totalizando 63 idosos. Aqueles inseridos no GE participaram de 10 OECA; os do GC1 assistiram 10 palestras com temática sobre o cuidado com a saúde na velhice, proferidas por membros da equipe multiprofissional da UMST-DF; e os do GC2, não receberam nenhum tipo de estimulação. Tanto nas OECA quanto nas palestras foi exigida frequência mínima de $70 \%$.

Foram realizadas entrevistas semiestruturadas antes das intervenções, coletando-se dados socioeconômico-demográficos. As mesmas foram feitas naqueles participantes do GC2 no mesmo período de tempo. Na segunda parte das entrevistas, efetuaram-se três perguntas: 1. Como estava sua memória há um ano em relação à sua memória atual? 2. Como está sua memória hoje? Comente (parte subjetiva). 3. Você acredita que sua memória é pior do que a dos outros? As duas últimas perguntas foram aplicadas aos participantes dos GE e GC1, nas pré e pós-oficinas e nas palestras, respectivamente. A avaliação da autopercepção da memória atual foi feita através da análise de conteúdo temática de Bardin ${ }^{(8)}$. Na análise dos comentários sobre o estado mnemônico no pós-teste, agruparam-se os relatos em categorias e subcategorias. Tal proposição destinou-se à compreensão das comunicações, significado das falas e entendimento das vivências dos idosos.

Aos participantes dos GE e GC1 foram oferecidas atividades uma vez por semana, com duração de duas horas. As OECA aplicadas no GE foram divididas em dois módulos, oferecidos na seguinte ordem: estimulação da memória de longo prazo e estimulação da memória de curto prazo. Justifica-se essa divisão devido à maior facilidade dos idosos recordarem acontecimentos distantes (memória de longo prazo) em relação aos recentes (memória de curto prazo) e, também, como forma de estimular o aprendizado, deixando-os mais confiantes e motivados para prosseguir até o término das oficinas, assim como permitir aos mesmos ter acesso a maior número de atividades e a diferentes tipos de jogos e brincadeiras.

A primeira oficina foi composta por jogos de apresentação e integração, com a intenção de incorporar o pesquisador ao grupo. Na última oficina utilizaram-se jogos de finalização, que forneceram oportunidade para avaliação do conjunto de oficinas. No início de cada oficina, foram recordados os temas dos encontros anteriores através de cartazes ilustrativos e perguntas direcionadas aos idosos, que podiam ajudar-se mutuamente no resgate de lembranças. Após esta atividade, era realizada apresentação teórica sobre o tema da oficina do dia, com duração 
de 10 minutos. Ao final de cada encontro, era proposta estratégia de estimulação cognitiva - tarefa de casa, em forma de exercício a ser realizado diariamente no domicílio, a fim de proporcionar contínua estimulação cognitiva durante aquela semana. Cada oficina foi composta por quatro tipos de jogos e/ ou brincadeiras específicas com a temática específica da oficina do dia. O último jogo ou brincadeira de cada encontro foi utilizado como plano de contingência, caso houvesse tempo livre, desmotivação ou qualquer outra intercorrência que fizesse necessária a substituição ou o acréscimo de atividades.

\section{RESULTADOS}

Os dados socioeconômicos e demográficos da amostra mostraram-se homogêneos entre os três grupos. A idade média foi de 72,86 $\pm 7,16$ anos. Os indivíduos muito idosos ( $\geq 80$ anos) constituíram $22 \%$ da amostra. Entre os idosos pesquisados, 58 (92\%) eram do sexo feminino. Não houve diferença significativa entre os três grupos quanto à faixa etária e sexo $(p=0,9)$.

Também não houve diferença significativa entre os três grupos $(p=0,07)$ quanto à situação conjugal, predominando os viúvos com 49,2\% (31 idosos), sendo apenas um deles do sexo masculino. Os idosos casados perfizeram $38,1 \%$ (24 idosos) da amostra e 12,7\% (8 idosos) eram solteiros ou divorciados.

A renda econômica foi semelhante nos três grupos, sem diferença significativa ( $p=0,61)$. Entre eles, 74,6\% (47 idosos) recebiam um salário mínimo e 15,9\% (10 idosos) não tinham renda alguma. A renda média foi de 0,97, isto é, menos de um salário mínimo.

Com relação às aposentadorias e pensões, também não houve diferença significativa entre os três grupos $(p=0,54)$. A aposentadoria foi citada em 36,5\% (23 idosos) da amostra, sendo $15,9 \%$ (10 idosos) dela constituída de não aposentados. Ao se somar o número de idosos que recebiam pensão dos cônjuges falecidos com aqueles que recebiam benefício da prestação continuada, totalizou-se 47,8\% (30 idosos) da amostra, valor que superou as aposentadorias por tempo de serviço/idade. No sexo feminino, as aposentadorias não eram das próprias mulheres sendo benefício indireto dos maridos, por as mesmas não terem sido inseridas no mercado de trabalho, não possuindo, portanto, renda própria.

Quanto à profissão/ocupação, também não houve diferença significativa entre os grupos $(p=0,64)$. Referindo-se os dados ao exercício anterior à aposentadoria, 82,5\% (52 idosos) eram trabalhadores do lar e 17,5\% (11 idosos) tinham outras profissões (autônomo, comerciário, diarista, lavrador e serviços gerais).

Quanto à moradia e ao arranjo familiar, também não houve diferença significativa entre os grupos $(p=0,64)$. Moravam acompanhados $86 \%$ da amostra, com a média de 2,33 $\pm 1,55$ pessoas por domicílio.

A análise da segunda parte das entrevistas, na qual foi pesquisada a autopercepção dos idosos sobre sua memória através de três perguntas, é descrita a seguir.

No pré-teste, as respostas à pergunta "Como estava sua memória há um ano em relação à sua memória atual?" forneceram os seguintes dados: no GE, $82 \%$ relataram que a memória estava melhor que a atual, $9 \%$ pior e $9 \%$ inalterada; no GC1, $81 \%$ referiram que a memória estava melhor que a atual, 9,5\% pior e 9,5\% inalterada; e no GC2, 85\% informaram que a memória estava melhor que a atual, $5 \%$ pior e $10 \%$ inalterada. A maioria dos idosos $(82 \%)$ teve a percepção de que sua memória estava melhor há um ano do que atualmente, ou seja, que houve piora desta durante o último ano (Gráfico 1).

As respostas à pergunta "Como está sua memória hoje?", feita no pré e pós-oficinas, mostraram diferença significativa $(p=0,03)$ no GE. Neste grupo, a maioria $(63 \%)$ dos idosos relatou que no pré-teste sua memória era regular, passando no pós-teste a ser percebida como boa (68\%). Verificou-se que $73 \%$ dos idosos apresentaram percepção positiva da memória (boa e excelente) após a realização das OECA, sendo que $41 \%$ deles mudaram de opinião, de memória ruim ou regular para boa. A resposta excelente permaneceu inalterada em 5\% deles (Gráfico 2).

No GC1, a análise das respostas à mesma pergunta feita no pré e pós-palestras também mostrou diferença significativa $(p=0,01)$. No pré-teste, $5 \%$ dos idosos deste grupo relataram que a memória era ruim, sendo esta percebida no pós-teste como regular por todos eles. Portanto, houve redução da resposta ruim e aumento da resposta regular, passando esta última a ocorrer em $76 \%$. da amostra. As respostas boa e excelente permaneceram inalteradas, com 19\% e 5\%, respectivamente (Gráfico 2).

No GC2, ao se comparar a percepção da memória atual, surgiu diferença significativa $(p=0,01)$ com tendência negativa. No pré-teste, $45 \%$ dos idosos deste grupo relataram que a memória era regular, diminuindo para $40 \%$ este grau de percepção no pós-teste, enquanto a percepção da memória como ruim aumentou de $20 \%$ para $25 \%$ do pré para o pós-teste, evidenciando aumento da autopercepção negativa da memória (Gráfico 2).

Nos três grupos surgiu alteração das respostas do primeiro para o segundo teste quanto à memória atual ser ruim, regular e boa, exceto quanto a ser excelente. Todos os resultados foram significativos intragrupos. Ao se compararem intergrupos quanto à memória atual, a percepção dos idosos mudou de forma positiva após a participação nas oficinas e palestras (GE e GC1, respectivamente), o que não ocorreu com o GC2 (sem intervenção), no qual predominou a percepção negativa da memória. O GE teve $41 \%$ de aumento na resposta "memória boa" no pós-teste, o que conseqüentemente reduziu a freqüência das respostas ruim e regular. O GC1 teve 5\% de aumento na emissão da resposta "memória regular", diminuindo a freqüência da resposta ruim. O GC2 aumentou a resposta "memória ruim", diminuindo a freqüência da resposta regular, ou seja, houve aumento da percepção negativa da memória atual nesse grupo.

As respostas à terceira pergunta "Você acredita que sua memória é pior do que a dos outros?", feita aos participantes do GE no pré e pós-oficinas, mostrou que a autopercepção da memória mostrou-se significativamente diferente $(p=0,01)$ nestes dois momentos. No pré-teste, $41 \%$ dos idosos desse grupo relataram que a memória era pior do que a dos outros, 


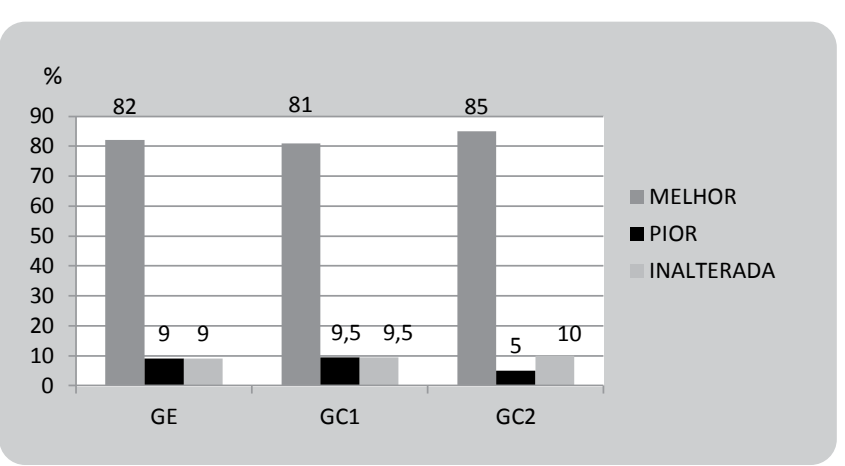

Gráfico 1 - Respostas à pergunta: "Como estava sua memória há um ano em relação à sua memória atual?", nos 63 idosos analfabetos com TCL, UMST-DF, 2010.

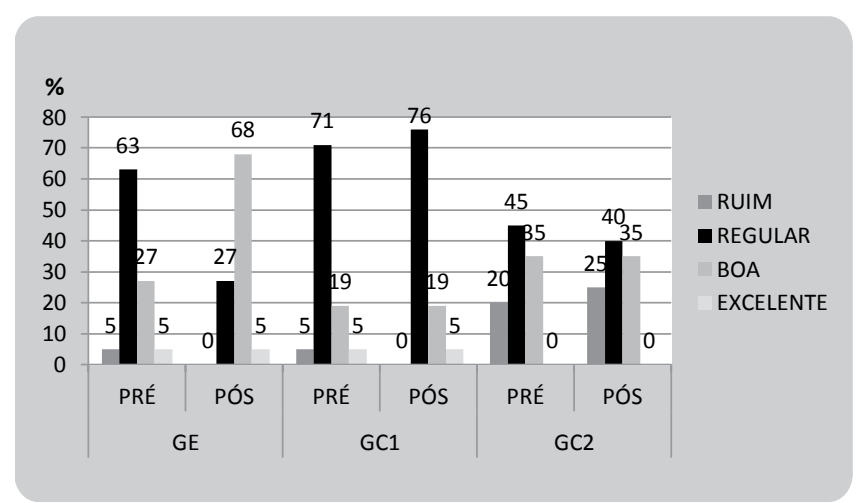

Gráfico 2 - Respostas à pergunta: "Como está sua memória hoje?", no pré e pós intervenções, nos 63 idosos analfabetos com TCL, UMST-DF, 2010.

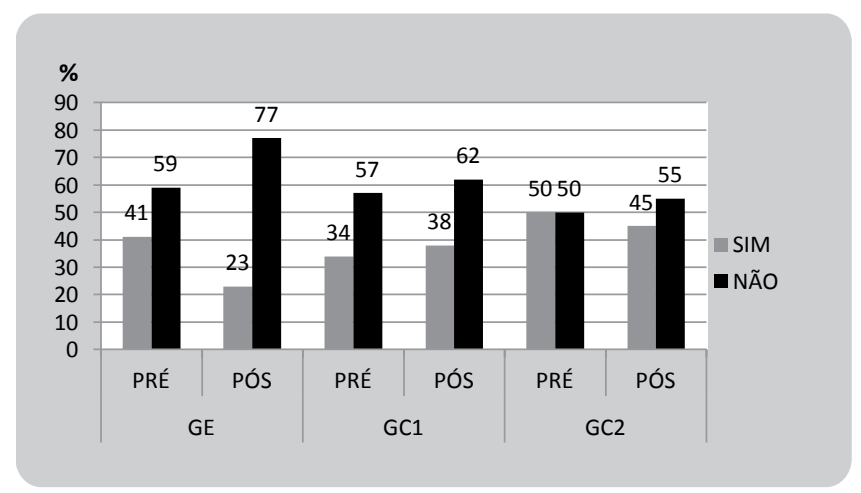

Gráfico 3 - Respostas à pergunta: "Você acredita que sua memória é pior do que a dos outros?", no pré e pós intervenções, nos 63 idosos analfabetos com TCL, UMST-DF, 2010.

enquanto no pós-teste somente $23 \%$ deles fizeram esse mesmo relato. No GE, surgiu diferença de $18 \%$ na resposta de que a memória não era pior do que a dos outros, portanto, aumentando a percepção positiva no segundo momento (pós-intervenção) (Gráfico 3).

Esta mesma pergunta feita aos participantes do GC1 mostrou que a percepção da memória em relação aos outros se revelou significativamente diferente $(p=0,01)$ no pré e pós-palestras. No pré-teste, $43 \%$ dos idosos relataram que sua memória era pior do que a dos outros, enquanto no pós-teste esta resposta foi dada por 38\% deles (Gráfico 3).

No GC2, a percepção da memória em relação aos outros demonstrou diferença significativa $(p=0,01)$ nos dois momentos estudados. No pré-teste, $50 \%$ dos idosos relataram que a memória era pior do que a dos outros, sendo este grau de percepção reduzido para 45\% no pós-teste (Gráfico 3).

Quanto aos comentários dos idosos sobre a autopercepção da memória no primeiro momento (pré-intervenção), os relatos nos três grupos foram realizados de forma simplista, usando poucas expressões e apresentando percepção pessimista da memória.

A análise dos comentários sobre o estado mnemônico no segundo momento (pós-intervenção) mostrou no GE: 1. melhora da cognição, da memória, atenção, pensamento e raciocínio; 2. socialização e integração, com convivência no grupo, redução da solidão e comunicação; 3. mudança nas AVD, sejam atividades domésticas ou as da vida social; 4. satisfação com as oficinas, com melhora do humor e contentamento. No GC1: 1. relatos dos mesmos esquecimentos, com dificuldades de lembrar e esquecimentos das AVD; 2. socialização e integração, conhecendo novas pessoas e participando de atividades na comunidade; 3. satisfação com as palestras, cuidando melhor da saúde. No GC2: 1. relatos dos mesmos esquecimentos, com desorientação no tempo e no espaço e esquecimentos nas AVD.

No GE, após as OECA, os idosos transformaram suas suposições iniciais em prática vivenciada, baseada no que sentiram, resignificando sua percepção mnemônica de forma positiva, que ficou mais expressiva e detalhada, com mais palavras, acrescentando adjetivos, relembrando e utilizando-se de exemplos da vida prática, apontando as melhoras e analisando de forma clara a percepção sobre sua memória.

No GC1 ficou evidente a manutenção dos mesmos esquecimentos, principalmente relacionados às AVD. Ressaltam-se aqui, a satisfação com as palestras por meio da subcategoria cuidar melhor da saúde, a ênfase dada à socialização com o conhecimento de novas pessoas, e o destaque à motivação em participar de atividades na comunidade.

No GC2, não foi evidenciada melhora na área da cognição, sendo mencionados pelos idosos os mesmos esquecimentos nas AVD e desorientação no tempo e no espaço. Estes idosos restringiram-se aos mesmos vocabulários, de forma resumida e com poucas palavras.

Os participantes do GE sobressaíram em relação aos GC1 e GC2, com referências de percepções positivas da memória em vários aspectos. $\mathrm{Na}$ análise deste grupo, observou-se o agrupamento de ideias e relatos em quatro categorias, havendo melhora na cognição, socialização/integração, mudança nas AVD e satisfação com as oficinas.

Nas habilidades cognitivas, como memória, atenção, pensamento e raciocínio, os idosos do GE relataram mudanças positivas, evidenciadas nas expressões de facilidade de lembrar e memorizar e na segurança com os afazeres e atividades cotidianas. No entanto, apesar destes idosos referirem melhora do déficit cognitivo, a dificuldade mnemônica melhorou, mas ainda persistiu. 


\section{DISCUSSÃO}

A memória não envelhece em idosos saudáveis. O que ocorre com frequência é que ela passa a ser menos exigida, piorando pela falta de uso. Para que ela seja conservada deve ser exercitada, assim como é importante fazer exercícios físicos e manter-se ativo. Exercitar a memória, assim como movimentar o corpo, devem ser atividades proporcionadas aos indivíduos idosos $^{(9,10)}$, o que foi feito na pesquisa atual com os participantes do GE.

Nesta pesquisa, $82 \%$ dos idosos analfabetos com TCL, quando questionados sobre como estava à memória há um ano em relação à atual, relataram piora da mesma ao longo do ano. Reforça-se, assim, a importância de identificação precoce de idosos com TCL, bem como a estimulação cognitiva aplicada nestes idosos.

Quanto se interrogou sobre o estado da memória atual, a percepção dos idosos mudou de forma positiva após sua participação nas oficinas e palestras (GE e GC1), o que não ocorreu com aqueles que não tiveram intervenção (GC2), nos quais houve até aumento da percepção negativa da memória. No GE, houve $41 \%$ de aumento na resposta "memória boa" no pós-teste, o que reduziu o número de respostas ruim e regular; no GC1, ocorreu $5 \%$ de aumento na emissão da resposta regular, diminuindo a freqüência da resposta ruim; entretanto, no GC2, aumentou a resposta "memória ruim", diminuindo a afluência da resposta regular, ou seja, houve aumento da percepção negativa da memória atual.

O mito de que o idoso não aprende está relacionado ao preconceito social contra essa faixa etária, à baixa autoestima do idoso e à falta de estimulação mental ${ }^{(10-14)}$. Percebe-se que o brincar, utilizando jogos e brincadeiras como atividades, facilita a aprendizagem e a prática de comportamentos específicos. Nas OECA oferecidas aos participantes do GE, foram incentivados: atenção, percepção, raciocínio, juízo, imaginação, pensamento, linguagem e memória. Estes quesitos levaram à diminuição dos distúrbios cognitivos nesses idosos analfabetos com TCL. As OECA ajudaram estes idosos, mas provavelmente não resolveram definitivamente seus distúrbios mnemônicos. Há necessidade de processo longo e continuado de estimulação em vários aspectos da cognição para que se mantenham os benefícios deste tipo de treinamento ${ }^{(15-16)}$.

Quando se analisaram as respostas à pergunta "Você acredita que sua memória é pior do que a dos outros?", verificou-se que os resultados foram positivos intragrupos. Na comparação intergrupos, surgiu maior alteração de resposta no GE em relação aos GC1 e GC2, reduzindo em 18\% a resposta de que a memória era pior do que a dos outros (41\% para $23 \%$ ). No entanto, os participantes do GC1 e GC2 também tiveram percepção reduzida de $5 \%$ de que sua memória era pior do que a dos outros (43\% para $38 \%$ e $50 \%$ para $45 \%$, respectivamente).

Os idosos do GE foram unânimes no relato de satisfação com as OECA. Esperava-se que surgissem benefícios produzidos pelas oficinas, visto terem sido utilizados jogos e brincadeiras que geram, além de aprendizagem e socialização, a satisfação que foi demonstrada através de gargalhadas, risos e sorrisos constantes durante a execução das mesmas. Todos os idosos do GE expressaram frases de contentamento, evidenciando melhora no estado de humor e emitiram expressões sentimentais, manifestadas como felicidade, alegria, bem-estar e animação.

Outro aspecto percebido por eles foi o despertar da diversão como parte integrante desta fase de suas vidas. O elemento lúdico das OECA lhe é inerente, redefinindo os níveis qualitativos existenciais. Planejar vivências lúdicas significativas e intervir a partir do lúdico sinaliza a (re) humanização do homem e da própria educação ${ }^{(17)}$. Estas alterações percebidas pelos idosos representam forte indício de que tais experiências podem ser capazes de resignificar, não apenas as vivências no âmbito do lazer, mas, também, proporcionar novo dimensionamento nos aspectos da vida em geral.

A satisfação com as lembranças do passado, através de canções, jogos e brincadeiras geraram, além da aprendizagem, a socialização, satisfação, bom humor e alegria, marcados durante as oficinas com a presença de gargalhadas, risos e sorrisos. Destaca-se, portanto, a importância em se trabalhar memória de longo prazo nas OECA.

Pesquisa realizada em 19 idosos, indagados sobre a importância de participar de programa de ação educativa voltado para idosos, todos responderam afirmativamente. Das alegações afirmativas figuraram, entre outros, registros de que nele adquiriram diversos aprendizados e sentiram-se importantes, valorizados, incentivados e animados. Além disso, afirmaram que nele puderam fazer novas amizades e conhecer mais pessoas. Além de se divertirem, distraíram-se e se sentiram bem, acreditando ser este um jeito novo de aprender a viver e que, mesmo depois de velhos, sempre estarão abertos a aprender ${ }^{(18)}$.

Quanto aos comentários dos idosos sobre a autopercepção da memória, no pré-teste os relatos dos participantes dos três grupos foram feitos de forma simples e pessimista. No pós-teste, os grupos controles mantiveram os mesmos esquecimentos, mas no GC1 (com palestras) foi dada ênfase à socialização e à motivação para participar de atividades na comunidade. $\mathrm{O}$ GE sobressaiu-se em relação aos demais grupos, destacando-se em quatro categorias: melhora na cognição, socialização/ integração, melhoria nas AVD e unânime satisfação com as OECA. Nas habilidades cognitivas, como memória, atenção, pensamento e raciocínio, os idosos do GE perceberam que obtiveram mudanças positivas, evidenciadas nas expressões de facilidade de lembrar e memorizar, assim como na segurança ao executar os afazeres e atividades.

Ênfase na socialização e na integração geraram relatos expressivos dos idosos participantes do GE, que identificaram nesses encontros um ambiente favorável ao convívio social, interação e lazer, com perspectivas de mudanças no futuro, criando incentivo e motivação para vivências mais felizes e participativas. Nas oficinas, os idosos puderam não só ouvir, mas principalmente se comunicar, falar e expressar o que sentiam, de se mostrarem desinibidos e à vontade dentro do grupo e no convívio social. Demonstraram expressivamente redução da solidão e a importância em suas vidas de fazerem novas amizades. Assim, o ganho pessoal e social da participação nas OECA foi percebido como importante por estes idosos. 
A satisfação gerada nas OECA pode estar também relacionada com fatos do passado desses idosos, pois estes os fazem relembrar situações vividas, através das canções e músicas de sua infância. Foi no passado, afinal, que eles estruturaram sua personalidade. Recordar vivências passadas é importante, pois a melhor maneira de não esquecer é lembrar, ou seja, quanto mais lembrar, mais o idoso vai vivenciar os fatos, melhor vai elaborá-los e, assim, melhor vai se sentir mesmo que não saiba explicar o motivo ${ }^{(19)}$. Trabalhando-se o passado, juntamente com o presente, pode-se fazer com que os idosos analfabetos sintam-se mais ajustados e com mais condições de encontrar satisfação. Destaca-se, portanto, a importância em se estimular a memória de longo e de curto prazo nessas OECA.

É relevante a disponibilização na rede pública de saúde de estratégias de estimulação cognitiva para idosos com TCL e, em particular, dos idosos analfabetos. No entanto para oferecer ao idoso com TCL uma atenção adequada, segura, ética e com qualidade, faz-se necessária a efetivação de políticas públicas que atendam as reais necessidades desta população, além da capacitação dos profissionais de enfermagem para o seu cuidado ${ }^{(20)}$.

\section{CONSIDERAÇÕES FINAIS}

O envelhecimento populacional tem levado a que os profissionais enfermeiros implementem cuidados aos sujeitos idosos visando melhorar sua qualidade de vida. Isto tem incentivado a realização de estudos que caracterizem melhor as deficiências dos idosos e investiguem as intervenções de enfermagem que mais se apliquem às situações clinicas desta população.

O presente estudo alcançou os objetivos, visto que evidenciou a autopercepção da memória em idosos analfabetos com TCL, antes e após a realização de OECA. Verificou-se que essas oficinas melhoraram a cognição, socialização/integração e as AVD dos idosos, fato de fundamental importância para a manutenção de sua funcionalidade em tarefas simples, como: lembrar-se de tomar os remédios, não deixar as panelas queimar, não esquecer o fogo acesso e lâmpadas ligadas, saber o que quer fazer ou pegar, pagar contas, fazer compras, etc. As atividades desenvolvidas nas OECA geraram atitudes contribuintes para manter a independência, diminuindo o risco da institucionalização. Os resultados são relevantes e positivos, pois demonstram que esse tipo de intervenção contribui para a promoção da saúde, autonomia e melhoria da qualidade de vida de sujeitos idosos analfabetos com TCL.

Essa pesquisa confirma a importância da estimulação cognitiva e destaca a lacuna deixada quanto à necessidade de realização de posteriores pesquisas, a fim de mensurar o tempo no qual perduram os benefícios adquiridos, bem como a continuidade de avaliação da percepção dos idosos por tempo mais prolongado após a realização das Oficinas de Estimulação Cognitiva para idosos analfabetos.

Enfatiza-se a necessidade de criação de espaços de vivência, objetivando a construção de uma cultura voltada para a melhoria da qualidade de vida desta da população idosa. Dessa forma, os profissionais responsáveis pela assistência prestadas a essa população devem estar orientados sobre a importância do cuidado integral e interdisciplinar.

Este trabalho vem a contribuir para a enfermagem no estímulo para o desenvolvimento de práticas alternativas de saúde para os idosos, bem como, para o incentivo à capacitação destes profissionais, que é de fundamental importância para o atendimento desta parcela considerável da população. Pauta-se também a colaboração para a enfermagem nos aspecto das pesquisas na área da cognição, envelhecimento e velhice.

\section{REFERÊNCIAS}

1. Instituto Brasileiro de Geografia e Estatística [homepage na internet]. Perfil dos idosos responsáveis pelos domicílios. [acesso em 22 mai 2010]. Disponível em: < http:// www.ibge.gov.br>

2. Ávila R, Bottino CMC. Atualização sobre alterações cognitivas em idosos com síndrome depressiva. Rev Bras Psiquiatr 2006;28(4):316-20.

3. Souza JN, Chaves EC, Caramelli P. O efeito do exercício de estimulação da memória em idosos saudáveis. Rev Esc Enferm USP 2005;39(1):13-19.

4. Zainaghi IA. Fosfolipase A, fluidez de membrana e proteína precursora do amilóide em plaquetas na doença de Alzheimer e comprometimento cognitivo leve. São Paulo. Tese [Doutorado em Ciências] - Universidade de São Paulo, 2006.

5. Gomes A M, Koszuoski R. Evidências atuais do impacto terapêutico dos inibidores da acetilcolinesterase no transtorno cognitivo leve e na demência vascular. Rev Psiquiatr RGS 2005;27 (2):197-205.

6. Yesavage JA, Brink TL, Rose TL, Lum O, Huang V, Adey $\mathrm{MB}$, et al. Development and validation of a geriatric depression screening scale: a preliminary report. J Psychiatry Res. Engl 1983;17(1):37-49.

7. Petersen RC, Stevens JC, Ganguli M, Tangalos EG, Cummings JL, DeKosky ST. Practice parameter: Early detection of dementia: Mild cognitive impairment (an evidence-based review). Neurol 2001;56 (9):1133-42.

8. Bardin NL. Análise de conteúdo. Lisboa, Edição 70, 2009, p.7-281.

9. Silva TBL, Oliveira ACV, Paulo DLV, Malagutti MP, Danzini VMP, Yassuda MS. Treino cognitivo para idosos baseado em estratégias de categorização e cálculos semeIhantes a tarefas do cotidiano. Rev Bras Geriatr Gerontol 2011;14(1):65-74.

10. Dias MSL, Moreno R. Estimulação cognitiva por meio de atividades físicas em idosas: examinando uma proposta de intervenção. Rev Bras Geriatr Gerontol 2012;15(2):325-34.

11. Irigaray TQ, Gomes Filho I, Schneider RH. Efeitos de um treino de atenção, memória e funções executivas na cognição de idosos saudáveis. Psicol Reflex Crit 2012;25(1):182-7. 
12. Siqueira RL, Botelho MIV, Coelho FMG. A velhice: algumas considerações teóricas e conceituais. Ciênc Saúde Coletiva 2002;7(4):899-906.

13. Santos, CC, Ortega AC. O papel dos esquemas na memória de idosas saudáveis. Psicol Estud 2012;17(2):267-76.

14. Ávila R, Bottino CMC. Atualização sobre alterações cognitivas em idosos com síndrome depressiva. Rev Bras Psiquiatr 2006;28(4):316-20.

15. Ball K, Berch DB, Helmers KF, Jobe J B, Leveck MD, Marsiske $M$, et al. Effects of cognitive training interventions with olders adults: a randomized controlled trial. JAMA 2002;2(18):2271-81.

16. Yassuda MS, Batistoni SST, Fortes AG, Neri AL. Treino de memória no idoso saudável: benefícios e mecanismos.
Psicol Reflex Crit 2006;19(3):470-81.

17. Matos NM. O significado do lúdico para os idosos. Brasília. Dissertação [Mestrado em Gerontologia]-Universidade Católica de Brasília; 2006.

18. De Gáspari, Campagna J, Schwartz GM. O idoso e a ressignificação emocional do lazer. Psicol Teor Pesq 2005;21(1):147-69.

19. Teixeira-Fabrício A, Lima-Silva TB, Kissaki PT, Vieira MG, Ordonez TN, Oliveira TB, et al. Treino cognitivo em adultos maduros e idosos: impacto de estratégias segundo faixas de escolaridade. Psico USF 2012;17(1):85-95.

20. Bueno FMG, Queiroz MS. O enfermeiro e a construção da autonomia profissional no processo de cuidar. Rev Bras Enferm 2006;59(2):222-7. 